\title{
Supporting Seniors in Independent and Healthy Ageing through ICT: Insights from a Value-Focused Thinking Study in Latvia, Poland and Sweden
}

\author{
Ewa Soja \\ Cracow University of Economics \\ Ewa.Soja@uek.krakow.pl
}

\author{
Marite Kirikova \\ Riga Technical University \\ Marite.Kirikova@rtu.lv
}

\author{
Piotr Soja \\ Cracow University of Economics \\ eisoja@cyf-kr.edu.pl
}

\author{
Ella Kolkowska \\ Örebro University \\ Ella.Kolkowska@oru.se
}

\author{
Agneta Muceniece \\ Riga Technical University \\ Agneta.Muceniece@edu.rtu.lv
}

\begin{abstract}
The 2019 WHO symposium on the future of digital health systems emphasized the importance of putting the individuals at the center of their own health and well-being. Consequently, strategies for active and healthy ageing should comply with older people's needs and requirements. In this paper, we applied the value-focused thinking approach to investigate the values held by seniors in Latvia, Poland and Sweden in the context of implementation of ICT for active and healthy ageing. Based on interviews with seniors, thirteen value-based objectives were identified and compared with domains of Active Ageing Index (AAI), a country-level measure of healthy and active ageing. The main findings imply that ICT is an important means of attaining the higher level of the AAI. To this end, taking into consideration value-based objectives held by seniors appears a necessary condition. Further, the results suggest that AAI index should be adjusted to the needs of seniors.
\end{abstract}

\section{Introduction}

Population ageing, defined as an increase in the share of older people in the population, is a distinctive phenomenon in developed countries and according to demographic projections for Europe will be deepening in time $[18,22]$. This situation creates a number of challenges for both the economy and society. In particular, many of the concerns involve projected increase of age-related expenditures including pensions, social and health care $[2,8]$. In Europe, to counteract these consequences, various strategies are now being developed, among which the policy of active ageing appears to be the most crucial. The most widely used definition of this strategy is provided by the World Health Organization [34] as "the process of optimizing opportunities for health, participation and security in order to enhance quality of life as people age". Active and healthy ageing strategies should be developed with the help of top-down public policies at the national and the local level, by initiatives from civil society organizations as well as by bottom-up behavioral responses by older people themselves [5, 32].

ICT can be a key tool in the development of strategies related to population ageing. In particular, it is pointed out that the principles defined to foster active and healthy ageing should include supporting people to live healthy, physically active lives and enhance their capacity to live independently through training, rehabilitation and the use of new technologies and to create age-friendly environments that aim to empower older citizens $[1,36]$.

Similarly, researchers developing new, more holistic care models emphasize a need for ensuring effective use of ICT applications based on user acceptability. However, they posit that although social care and informal care are essential to improving health and preventing health problems, especially in an ageing population, there are still large gaps of knowledge in how best to organize this, and how best to combine it with health care. Specifically, improving health and general wellbeing via welfare technology, optimizing the division of labor between different forms of care, is an underdeveloped area in both research and policy [24]. Similarly, two out of three key messages of the WHO Symposium on the Future of Digital Health Systems in the European Region [35] emphasize the need for transition of digital health care to predictive and preventive models of care and indicate that digitalization of health systems should put the individual at the center of their own health and well-being. 
To evaluate current activities and to set targets and monitor progress towards the policy of active and healthy ageing in the future, Active Ageing Index (AAI) is often used. However, although the importance of ICT for the implemented strategies is pointed out, the definition of the AAI index is to only a limited extent associated with ICT [36]. Another criticism directed to AAI is that the index is composed without taking into consideration the needs and wishes of older people [31] and also that the index tends to focus on the experiences of the 'young old' [6]. Including the perspective of seniors is also in line with the need to expand or modify AAI, which was suggested in the past but not yet adequately addressed, in order to avoid the trap of considering all older people as a homogeneous group [25, 31].

Prior studies indicated that countries differ in the degree of implementation of active ageing and levels of development of the digital economy and society [4, 36]. In particular, research conducted in European countries such as Latvia, Poland and Sweden, revealed that seniors differ with respect to the required types of digital solutions supporting everyday life as people age [27]. These results, however, do not give insight into the motivations of older people that would allow better preparation of age-friendly environments supported by new technology that aim to improve the activity, independence and autonomy of older people.

Against this backdrop, our study aims to investigate the values of older people (65-85) in Latvia, Poland and Sweden in the context of implementation of ICT for active and healthy ageing and indicate recommendations for better implementation of active ageing strategies. These countries belong to different country clusters regarding both implementation of active ageing [31] and levels of development of the digital economy and society [27].

To identify seniors' values, this study applies value-focused thinking (VFT) approach [12], which is a way of improving decision-making in a specific context by grounding strategic decisions in values identified in that context. VFT can be used for formulating objectives based on values held by different stakeholders [7] and was successfully adopted by several IS scholars [e.g. 9, 19]. Our study focuses on older adults and seeks to answer the following research questions: (1) What value-based objectives are important for seniors in Latvia, Poland and Sweden in the context of implementation of ICT for active and healthy ageing? (2) What are the differences and similarities between the identified value-based objectives in these countries? (3) How the value-based objectives correspond to domains of Active Ageing Index?

\section{Background}

Active Ageing Index (AAI) was developed and launched in 2012 as a result of the joint research project of the United Nations Economic Commission for Europe, the European Commission's Directorate General for Employment and Social Affairs and Inclusion, and the European Centre for Social Welfare Policy and Research in Vienna. The project has aimed at providing a new tool for policymakers to enable them to devise evidence-informed strategies in dealing with the challenges of population ageing and its impacts on society [31]. AAI was calculated as the weighted average of the four AAI domains: Employment (35\%), Social Participation (35\%), Independent Living (10\%), and Capacity for Active Ageing (20\%). AAI is constructed from 22 individual indicators grouped in these four domains. For each domain, individual indexes were calculated and were estimated as the weighted average of individual indicators. The first three domains together measure the 'actual experiences' of active ageing. The fourth domain measures the starting conditions for achieving positive active ageing outcomes. The Employment domain includes employment rates for people from 55 to 74 years. The Social Participation domain refers to voluntary activities, care to children and older adults, and political participation. The Independent Living domain refers to access to health services, independent living arrangements, financial security, physical safety, and lifelong learning. The Capacity for Active Ageing domain pertains to healthy life expectancy, mental well-being, use of ICT, social connectedness, and education [36].

The numerical value of the AAI can be interpreted as the extent to which older people participate in the economy and society to live independently and have the capacity for active and healthy ageing. A higher level of AAI indicates a more favorable situation. The most recent results of the AAI for Latvia, Poland and Sweden, calculated on the basis of the latest available data (2016), are illustrated in Table 1. The situation in Poland looks the worst, except for the Independent Living domain, which is better than in Latvia. The capacities for active and healthy ageing in Latvia and Poland are similar, but much worse than in Sweden.

As mentioned earlier, although the importance of ICT for the implemented strategies is pointed out, only one out of four domains of AAI included one very simple factor being in direct connection with ICT (i.e. use of Internet by older people). This measure has a weight of $7 \%$ in the Capacity for Active Ageing domain and is measured by share of people aged 55-74 who use the Internet at least once a week $[31,36]$. 
Table 1. Countries' Comparison

\begin{tabular}{|l|c|c|c|}
\hline & Latvia & Poland & Sweden \\
\hline \multicolumn{4}{|c|}{ Life expectancy at birth / Healthy life years at birth - 2018* } \\
\hline Female & $79.7 / 53.7$ & $81.7 / 64.3$ & $84.3 / 72.0$ \\
\hline Male & $70.1 / 51.0$ & $73.7 / 60.5$ & $80.9 / 73.7$ \\
\hline \multicolumn{4}{|c|}{ Life expectancy at 65/ Healthy life years at 65 - 2018* } \\
\hline Female & $19.0 / 4.7$ & $20.1 / 8.8$ & $21.6 / 15.8$ \\
\hline Male & $14.1 / 4.2$ & $15.8 / 8.2$ & $19.2 / 15.6$ \\
\hline \multicolumn{4}{|c|}{ 2018 Total Active Ageing Index (AAI) and AAI domains** } \\
\hline Total AAI (change 2008-2016) & $35.7(+4.6)$ & $31.5(+4.2)$ & $46.9(+3.3)$ \\
\hline (I) Employment (35\%) & 37.7 & 26.5 & 45.4 \\
\hline (II) Social Participation (35\%) & 17.8 & 13.1 & 26.0 \\
\hline (III) Independent Living (10\%) & 61.6 & 71.6 & 76.9 \\
\hline (IV) Capacity for Active Ageing (20\%) & 50.2 & 52.7 & 71.2 \\
\hline
\end{tabular}

Notes: *based on Eurostat database, **based on [31].

Researchers indicated that active ageing strategies in practice have been dominated mainly by a narrow economic perspective that prioritizes mainly the extension of working life. They suggested that active ageing should encompass all older people, including those who are frail and dependent because a focus only on the "young-old" is likely to exclude the people in a more advance age ("old-old"). Therefore, "activity" should include all meaningful pursuits that contribute to individual well-being, such as paid employment, volunteering, as well as an engagement in leisure activities [5, 25, 32].

To recognize the values of seniors, we decided to refer to people aged from 65 to 85 due to various reasons. First, it is not self-evident how to conceptualize and operationalize the "old-old" and several different age groups have been used in earlier research and policy document (e.g. 75+ in Swedish research) [6]. Second, this age group includes people who ended or are about to end their professional activity. Third, in our case, we study older adults from three countries which differ significantly in terms of life expectancy and healthy life years that are important physical-health measures of population ageing and are used widely by WHO, UN, and other international agencies, such as the Institute for Health Metrics Evaluation [26]. The detailed data is presented in Table 1.

The values of life expectancy at birth and healthy life years at birth show that the health condition of Swedes is the best while Latvians are in the worst health condition. For Latvians, about 10 years before the end of working age the so-called healthy life ends. Swedes, in turn, have statistically healthy life years longer than the normative retirement age. Similarly, the life expectancy of 65-year-olds in Sweden is the longest, but significant differences are visible for healthy years, and especially for men. Such differences affect the perception of help in an active and healthy life, or the need to develop a given type of digital solutions [16, 27]. Therefore, we believe that the adopted age group is adequate to investigate possible differences in the perception of value (preferences) in the context of "activities" and ICT that can change with increasing age due to health constraints [5].

The concept of value is complex and may be understood and explained differently in various areas of science. In this study, we adopt Keeney's [12, 13] definition of values as ethical principles guiding evaluation of choices "principles for evaluating the desirability of any possible alternatives or consequences'. Values exist on both collective and individual levels [10,23]. Collective values are values that an individual shares with other people within, for example, a culture, group or organization [10]. Researchers argue that it is both possible and useful to describe the central tendencies of acting within a group by analyzing values held by individuals within a collective $[3,15,30,33]$. Thus, in this study, values are studied on an individual level in order to understand and identify collective values that are shared within a group of seniors in each of the studied countries.

Value-focused thinking (VFT), applied in this study as a way of identifying individual values of seniors, was put forward by Keeney [12] to improve decision-making in a specific context by grounding strategic decisions in values identified in that context. This approach is different from traditional (problemsolving) methods for decision-making. In the VFT approach, decision makers are forced to identify 'what they care about', whereas in traditional approaches they base their choice of a solution on availability [12]. In this way, the value-focused thinking approach helps decision makers to be proactive in decision making by creating value-based options instead of being limited to the available alternatives. 


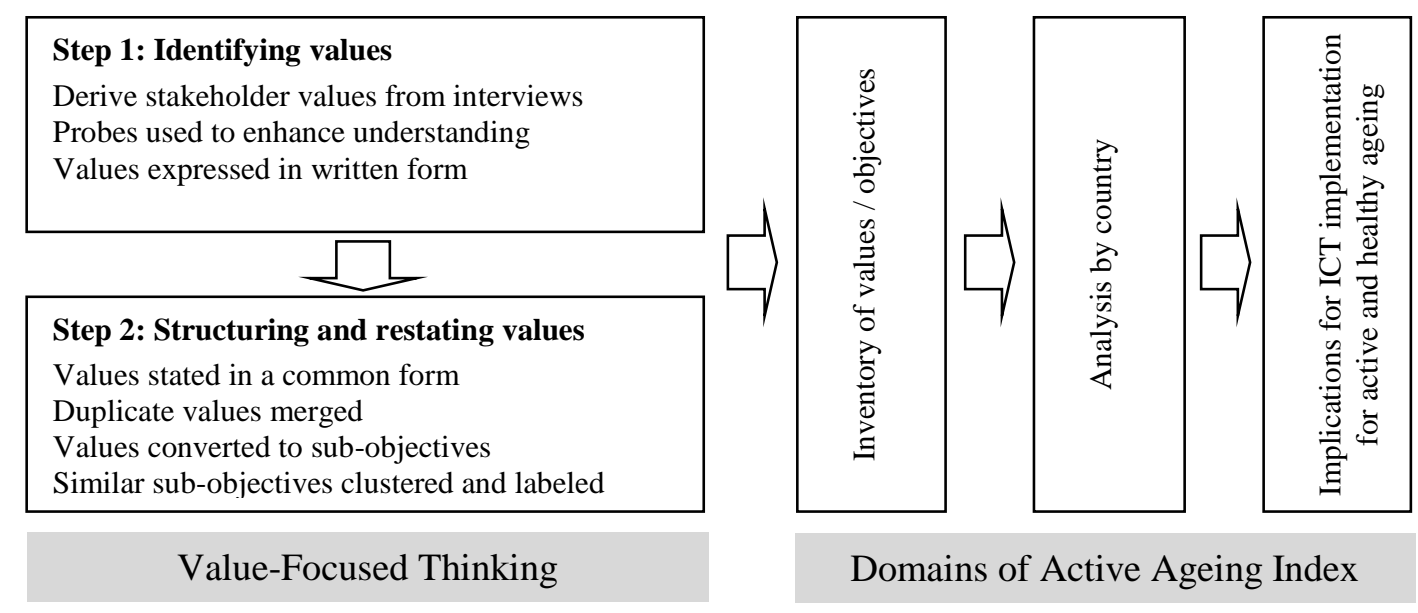

Figure 1. Research Approach

According to the VFT approach, any thoughts about possible decisions should begin with values [12]. VFT has also been used for creating strategies based on values held by different stakeholders [7]. In the context of our study we identify values of seniors' to inform strategies for active and healthy ageing supported by ICT.

\section{Method}

The current study focuses on Latvia, Poland, and Sweden, and the reasons behind choosing these countries were manifold. First and foremost, the selected countries demonstrate significant differences with respect to various technology-related and socioeconomic considerations [27]. In particular, Poland and Latvia reveal the considerations of transition economies [28], while Sweden belongs to the group of the most industrialized countries. The countries considered in the current study also experience different organization of the healthcare system. In particular, the Swedish system is built on state responsibility model with a strong emphasis on redistribution, social inclusion and universality of public services. In Poland and Latvia, only some of the care needs are satisfied by the government, while other services are rendered by families and private service organizations [e.g. 14, 29].

Figure 1 describes our research approach, which starts with identification of seniors' individual values, deemed important for seniors in Latvia, Poland and Sweden in the context of ICT for healthy and active ageing. The values are then transformed into valuebased objectives, which are compared with domains of AAI on a country level. Finally, based on the analysis we formulate implications for ICT implementation for active and healthy ageing.

In the first part of our study, individual values held by seniors in the three studied countries were identified and transformed into value-based objectives in-line with the VFT approach. According to VFT, the process of identifying value-based objectives starts with individual interviews with the concerned people (in our study seniors). We conducted in-depth interviews with 15 seniors in each of the studied countries. To ensure a relatively good representativeness and diversity of samples, we have chosen respondents of both genders (7 men and 8 women in each country), aged 65-85, with different places of residence (i.e. city, suburbs, rural area) and varied health status (i.e. subjective evaluation from excellent to bad health status).

The interviews were conducted following the VFT-approach [12]. The interviews focused on the seniors' preferences regarding implementation and use of ICT for active and healthy ageing and each interview started with clarifying the purpose and scope of the interview. The respondents were assured that no personal data will be disclosed and their opinions will be used solely for research purposes. Our investigation belongs to pre-implementation studies, which typically use presentations to explain different types of technology for ageing in place (welfare technology) (e.g., health monitoring technologies, monitoring and alarming technologies, memory supporting technology, technology assisting independent eating) to the respondents [21]. Such a solution has also been applied during our data gathering process. To help the respondents in expressing their values we used words suggested by Keeney [12] such as trade-offs, consequences, impacts, concerns, fair and balance. The interviews were then transcribed and analyzed. To 
identify individual values in the collected material, we focused on statements expressing problems, consequences, better or worse alternatives, or goals. The analysis resulted in a list of statements that were numbered, written as values, and input into a database. We have identified 175 statements expressing values in Latvia, 359 Poland and 280 in Sweden.

The identified values were then structured and all duplicates were merged into the common categories. After that, all values were translated into objectives in line with VFT. As for example, a value "it is important that seniors reveal positive attitudes towards technology" was transformed to an objective "ensure seniors' positive attitudes towards technology" or a value "a senior should feel safe" was transformed into an objective "maximize seniors' safety". Then, the value-based objectives were analyzed to identify those objectives that deal with similar issues. All objectives dealing with similar issues were categorized into categories, which were labeled. First, the objectives were categorized separately for each country. Then, the categories identified in each country were discussed in a group of researchers involved in this study, any inconsistencies were agreed upon, and common crosscountries categories were created. To evaluate the level of perception by country we used the distribution of statements defining the categories.

In the second part of our study, using common cross-countries categories, we discovered issues for which new indicators within AAI domains should be created or those existing extended in order to capture the context of using ICT for active and healthy ageing. Next, in order to see what aspects are emphasized by the seniors in Latvia, Poland and Sweden in relation to each of the AAI domains, the value-based objectives were mapped on the AAI domains. Finally, based on the analysis, implications for strategies for active and healthy ageing have been formulated.

\section{Results}

\subsection{Seniors' Value-based Objectives in the Studied Countries}

The value-based objectives discerned from interviews with the respondents are shortly described in the following paragraphs.

Enhance seniors' digital inclusion - Seniors in Sweden and Latvia emphasized the importance of taking special precautions for preventing seniors' exclusion from the digital community. They stress that it is important to offer an opportunity for the seniors to keep up with technology by providing information, focused training, increasing awareness, develop ICT skills and involving seniors in development of ICT solutions.

Ensure acceptance by seniors - Seniors in all three countries pointed out that it is important that seniors reveal positive attitudes towards technology and are willing to accept it. To ensure acceptance by the seniors, a number of solutions should be available (seniors can choose among various options). It is important to have an opportunity to test the solution and to learn how it operates. An accessible instruction manual should be available. The seniors should give their consent to use the technology; they should trust and not be afraid to use the technology. They should have confidence in using the ICT solution.

Ensure alignment with seniors' needs - Seniors in all three countries stressed that the technology should be easy to operate, comfortable, easy to learn, and adjusted to the seniors' needs. The technical solutions must be useful (addressing the senior's actual needs). The technology should support seniors in their daily life at home. The supporting digital solutions should be able to react without human operation and an older adult should not be forced to remember to bring it with him/her. Many different solutions should exist so it is possible to choose the most suitable for each situation. Still, traditional ways of doing things should be possible to choose if so required.

Ensure privacy and data security - Seniors in Sweden and Poland pointed out that the technology should guarantee data security and should ensure people's privacy. It is important to consider both the seniors' and their partners' privacy when the new ICT solutions are implemented in their homes. Seniors want to be informed about the extent of monitoring, as well as how the information is handled and who can access the information.

Improve the quality of care - Seniors in all three countries emphasized the importance of using ICT for more efficient use of existing resources (personnel's time), for improving accessibility to care professionals and facilitating face-to-face interaction. The digital solutions should provide fast information on the condition of health. It is essential to receive fast and well-timed help. The solution should ensure better prevention and 24/7 care. Care should be easier, more accessible, less time consuming, and cheap. The solution should help to minimize health appointments. It is also important not to be completely dependent on the technology but also have access to traditional (involving people) type of care.

Increase independence and autonomy of seniors - Polish and Swedish seniors' stressed that the technology should foster self-dependence of the seniors and should help them not to be a burden for the family. The seniors emphasized the importance of 
being aware of their health condition and being able to check their health status unaided. Our respondents stated that it is important that the solutions can enhance seniors' safety, help the seniors not to get lost, detect fall, raise an alarm and facilitate communication with family and caregivers. The seniors should be able to live independently in their homes, in well-known settings, close to their friends and neighbors, among things and places they like (as opposed to moving to a care institution). The seniors also emphasized the importance of being able to decide about all aspects of their lives, i.e. where they live (at home, at an institution), what kind of help they get (digital or traditional), and to what extent they reveal information about themselves (balance between privacy and safety).

Increase seniors' activity - Seniors in all three countries underlined the important role of ICT in enhancing their activity. They stressed, for instance, that apps and/or social robots could inspire them to physical activity. They also pointed out that ICT solutions could enhance their involvement in different interest groups, interaction with other people, and political discussion. The seniors stressed further that it is fun to learn new things related to ICT (selfdevelopment) and that those who are skilled could help others.

Maximize mental well-being - The seniors in Sweden and Poland emphasized the importance of feeling safe and being needed. The seniors stressed that an older person should have a sense of safety and security, should not feel anxiety nor be lost. An older person should feel needed and be appreciated and should not be afraid of being alone at home.

Maximize availability of ICT solutions - Our respondents from all three countries pointed out that there is a need for developing relatively cheap and simple everyday digital solutions that seniors could afford. For the other, more complex and expensive solutions (such as social robots, health care systems, etc.) sufficient payment models need to be developed. Generally, such solutions should be provided by municipalities together with sufficient training and support. It is essential to popularize the solution and have Internet access at home. It is important that municipalities invest in development of ICT in various areas and that the solutions are implemented in future homes and care institutions as a standard equipment.

Maximize quality of ICT solutions - Seniors in all countries underlined that the ICT solution should be reliable, should operate quickly and should undergo regular inspections. It is important that it works without any technical errors and show correct data. Alternative ways of doing things must exist in case of emergency such as power cut. In addition, someone must respond to alarms otherwise the solutions are not reliable even if they work without technical errors.

Maximize usefulness for various stakeholders Our respondents in all three counties stressed that ICT solutions should be helpful for formal and informal caregivers by helping them to operate more efficiently, to reduce their anxiety and increase the feeling of safety and security. ICT solutions should support informal caregivers so that they are able to combine the work with the care duties but also have more spare time. Digitalization of elderly care should help national economy to develop. Companies delivering ICT solutions supporting an active and healthy ageing should be established and supported by the government.

Minimize loneliness - Implementation of the new ICT solutions is seen by the seniors in all three countries as a means to reduce loneliness by enhancing social contact and supporting social interaction with family and other people. The seniors should be able to communicate with other people and should not be excluded from the society. In this context, the seniors mentioned online games designed for their needs, interactive social robots, and different kinds of communication tools that would help them to be closer to their family and friends. In addition, the seniors emphasized the importance of physical contact with other people, "to have someone to share daily activities with."

Raise awareness of technology impact - Seniors in all studied countries pointed out that careless implementation of ICT can have a negative impact on seniors' lives, dignity, and well-being. People should be ready to help the elderly and should understand potential consequences of loneliness. There is a need to make people aware of the consequences of the solution misuse. Therefore, long-term social consequences of ICT implementations should be considered and analyzed. The seniors pointed out that ICT might change our way of thinking, professional roles, family relationships, etc. Thus, the new ICT solutions should be implemented thoughtfully, based on informed decisions.

Overall, 9 out of 13 value-based objectives in the context of ICT for active and healthy ageing have been identified in all countries, though their perceptions differed by country, except for the objective Ensure acceptance by seniors. The varied perceptions of objectives depending on country, defined by the distribution of statements defining the objectives for each country, have been summarized in Table 2 . Latvians emphasize to the greatest extent alignment of ICT to seniors' needs, seniors' activity, quality of ICT solutions, and awareness of technology impact. Poles to a significant extent highlighted the importance of the 
quality of care, independence of seniors, minimization of loneliness, and solutions' usefulness for various stakeholders. Swedes to the greatest extent perceived the importance of independence and autonomy and alignment of ICT to seniors' needs.

Table 2. Values by Country

\begin{tabular}{|c|c|c|c|}
\hline Value-based Objective & $\mathbf{L V}$ & PL & SE \\
\hline Enhance seniors' digital inclusion & - & & ○ \\
\hline Ensure acceptance by seniors & (1) & (1) & ( \\
\hline $\begin{array}{l}\text { Ensure alignment with seniors' } \\
\text { needs }\end{array}$ & $\bullet$ & ○ & 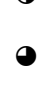 \\
\hline Ensure privacy and data security & & ○ & ○ \\
\hline Improve the quality of care & - & $\bullet$ & - \\
\hline $\begin{array}{l}\text { Increase independence and } \\
\text { autonomy of seniors }\end{array}$ & & $\bullet$ & $\boldsymbol{\theta}$ \\
\hline Increase seniors' activity & $\boldsymbol{\bullet}$ & 0 & - \\
\hline Maximize mental well-being & & - & ○ \\
\hline $\begin{array}{l}\text { Maximize availability of ICT } \\
\text { solutions }\end{array}$ & ○ & ( & - \\
\hline Maximize quality of ICT solutions & $\boldsymbol{0}$ & 0 & ○ \\
\hline $\begin{array}{l}\text { Maximize usefulness for various } \\
\text { stakeholders }\end{array}$ & ○ & $\bullet$ & ○ \\
\hline Minimize loneliness & - & $\bullet$ & - \\
\hline $\begin{array}{l}\text { Raise awareness of technology } \\
\text { impact }\end{array}$ & - & $\odot$ & - \\
\hline
\end{tabular}

Note: $\bullet$ high, $\bullet$ medium, $\mathbf{0}$ low, $\odot$ very low perception.

The main and somewhat surprising difference was the lack of emphasis put by Latvians on the importance of independence and autonomy, which were very significant for Poles and Swedes. Perhaps this can be associated with the much shorter so-called healthy life of Latvians, who statistically have to deal with diseases almost 10 years before leaving work. Accustomed to dealing with health problems, they might perceive the role of ICT as more significant for the needs of everyday life (emphasizing alignment and quality of ICT) than for strengthening autonomy or independence. This explanation can additionally be supported by the fact that the Latvian group was a little younger (median age for Latvia - 72, for Poland and Sweden - 78).

\subsection{Mapping Values on Active Ageing Index}

Comparing common cross-countries categories with AAI domains, we have found that most valuebased objectives can be combined mainly with domains III and IV (Independent Living and Capacity for Active Ageing). However, the two categories: Raise awareness of technology impact and Maximize usefulness for various stakeholders, which mainly concern the environment needed for active and healthy ageing in the context of the use of ICT (i.e. domain IV), have no reference in current indicators describing this domain. Similarly, some aspects of the category Increase seniors' activity, related to domain II (Social Participation) do not have a suitable representative in current indicators. Five value-based objectives (Maximize quality of ICT solutions, Maximize availability of ICT solutions, Ensure privacy and data security, Enhance seniors' digital inclusion, Ensure acceptance by seniors) that are essentially related to the use of ICT by seniors (an area in the domain IV), clearly show that the measure used to assess this area should be significantly expanded to be able to monitor the possibilities of supporting active ageing by new technologies. There were no value-based objectives that directly supported the Employment domain. Table 3 shows the mapping of respondent values on AAI's domains in individual countries.

Table 3. Mapping Values on AAI Index Domains

\begin{tabular}{l|lll}
\hline AAI domain & LV & PL & SE \\
\hline Social Participation & & & \\
Capacity for Active Ageing & & & \\
Independent Living & & & \\
Employment & & & \\
\hline
\end{tabular}

The discussed above relationships between common values and AAI domains relate to a large extent to each of the countries studied and describe similarities between the countries. Given the individual differences between countries, it should be noticed that in Poland more value-based objectives can be linked to healthcare-related areas than in Latvia and Sweden. These are Access to health services in the domain II and a potentially new area related to usefulness for various stakeholders in the domain IV. The latter also concerned Latvia and Sweden, but to a lesser extent. This is due to the fact that the models for elderly care, as well as the level of available funds allocated by the state for elderly care, differ in the studied countries. The situation in Poland is the most difficult as Poland belongs to the group of countries with the leastdeveloped care organization and the lowest level of funds allocated for elderly care [17]. Some differences also apply to new areas in the domains II and IV of AAI, which were found more evident for pairs of countries. In the domain II of AAI, the area related to entertainment was revealed in Sweden and Latvia, in the domain IV the area related to technology awareness in Poland and Sweden, and the area related to business development in Latvia and Poland. 


\section{Discussion and Implications}

The most important finding from the current research is that ICT's role to attain the AAI is ignored in the current AAI's domains and indicators. On the contrary, the seniors participating in this research see ICT as a powerful and important means enabling them to cope with ageing and participate in the society. Our study shows that the seniors acknowledge the important role of ICT in finding new ways to engage in social and pro-health activities that are aligned with their needs, health status and possibilities to be able to independently live a healthy and secure life. Based on our findings we argue that ICT is an important means of attaining the higher level of the AAI and the strategies implementing ICT should be formulated based on value-based objectives expressed by the main stakeholders. Additional implications which emerge from our study are shortly explained in the following paragraphs.

First, taking into consideration the solutions' availability and usability for various stakeholders, our findings illustrate the need for interconnection between healthcare and preventive care services. In this respect, the interviewed seniors do not perceive themselves as only patients. Based on their opinions, we might posit that social care and healthcare systems need to be interlinked and better accessible not only to seniors but also to formal and informal caregivers.

Second, the AAI index is not adjusted to the need of the oldest old. Our study shows that most of the values emphasized as important by the seniors in the context of active and healthy ageing are related to domains III (Independent Living) and IV (Capacity for Active Ageing), which are weighted least in the AAI (10\% and $20 \%$, respectively). On the contrary, the two domains that are weighted highest in the AAI; Employment (35\%) and Social Participation (35\%) received least attention from the seniors in the study. Our study suggests that domains III and IV should be weighted higher than domains I and II, when the AAI is used to evaluate activities and monitor progress towards the policy of active and healthy ageing considering the seniors. Furthermore, our findings indicate that the seniors are not so interested in paid employment or volunteering activities but emphasize the importance of engagement in meaningful and appropriate for this group leisure activities. This is in line with the paramount importance of leisure activities indicated by prior research. In this respect, Ihle et al. [11] posit that leisure activities have a positive impact on physical health, while lack of participation in purposeful leisure time may be indicative of poor general health in later life [20]. Our findings are in line with previous studies showing that AAI need to be extended and adjusted to the needs of seniors [6]. Our study contributes to the previous research by showing that the need for adjustment of AAI appears in several countries such as Sweden, Poland, and Latvia. In this respect, Fritzell et al.'s [6] study was conducted only in Sweden.

Third, strategies for active and healthy ageing should be formulated based on value-based objectives expressed by the main stakeholders. Based on our analysis we can conclude that the policy-makers' intentions are not always in line with what seniors consider as important in the context of active and healthy ageing. The dominating narrow economic perspective that prioritizes mainly the extension of working life is apparently not what the seniors care about. Our study shows that several of the identified value-based objectives do not have references in current indicators describing AAI domains. Such objectives are, for instance, Raise awareness of technology impact, Maximize usefulness for various stakeholders, and Enhance seniors' digital inclusion. In relation to the last example, the seniors emphasized for instance the importance of taking special precautions for preventing seniors' exclusion from the digital community. Further, they stress that it is important to offer an opportunity for the seniors to keep up with technology by providing information, delivering focused training, increasing awareness, developing ICT skills and involving seniors in development of ICT solutions. Identifying these individual and cultural preferences enriches the narrow economic perspective currently applied in the existing strategies. The seniors seem to perceive themselves as active participants in the society who are able to change capacities and contribute to enabling environment for active ageing. It is important that strategies for active and healthy ageing encompass this positive tendency to transformation. AAI focuses more on measurements of the 'actual experiences' of active ageing (domains IIII) and the conditions for achieving positive active ageing outcomes (domain IV), and views seniors as more passive i.e. "use of Internet by older aged 55-74 at least once a week".

Fourth, ICT should play a significant role in formulating policies for active and healthy ageing. Our respondents identified various value-based objectives (Maximize quality of ICT solutions, Maximize availability of ICT solutions, Ensure privacy and data security, Enhance seniors' digital inclusion, Ensure acceptance by seniors) that could complement the indicator for use of ICT by seniors (an area in the domain IV of AAI). Seniors in Poland, Sweden and Latvia emphasized the huge potential of ICT in relation to other domains such as participation in society (domain II), independent and secure living (domain III) 
as well as capacity and enabling environment for active ageing (domain IV). According to the seniors and their values, ICT solutions could, among other things, improve the quality of care, increase independence and autonomy of seniors, increase seniors' activity, maximize mental well-being and minimize loneliness.

Finally, we would like to point out that the seniors who participated in this study were both willing and interested in discussing the role of ICT in strategies for active and healthy ageing. They were also capable of expressing various significant ICT-related suggestions in this context. Thus, the common assumption that older people lack willingness, sufficient (technical) knowledge and awareness to be able to discuss ICT solutions might be misleading and prevent policymakers from acknowledging the significant role that ICT could play in strategies for active and healthy ageing.

\section{Conclusion}

In this paper, we have applied value-focused thinking [12] to investigate the values of older people (aged 65-85) in Latvia, Poland and Sweden in the context of implementation of ICT for active and healthy ageing. Then, we indicated recommendations for better implementation of active ageing strategies. While majority of strategies for active and healthy policies are developed based on Active Ageing Index (AAI) evaluations, we suggest that the strategies should be formulated based on values held by key stakeholders within this context. Our results show that 9 out of 13 value-based objectives in the context of ICT for active and healthy ageing have been identified in all three countries, though their perception levels differed between the studied countries. The differences may depend on socio-economic factors such as the level of economic and digital development, health status of older population and solutions in the field of social and health policy. The comparison of the identified value-based objectives with AAI domains revealed that the value-based objectives can be mainly combined with two out of four AAI domains (Independent Living and Capacity for Active Ageing). The comparison also showed that the identified valuebased objectives can extend the domains of AAI and adjust the indicators to the needs of older seniors. In summary, the paper offers four key findings: 1) ICTs is an important means of attaining the higher level of AAI; 2) The AAI index should be adjusted to the needs of the oldest old; 3) Strategies for active and healthy ageing should be formulated based on value-based objectives expressed by the main stakeholders; 4) ICT should play a significant role in formulating policies for active and healthy ageing. The main limitation of the current study is associated with the limited number of respondents, i.e. 15 for each country investigated, which limits the generalization of findings. Nevertheless, in this respect we should bear in mind that 15 was the mean number of respondents interviewed during in-depth interviews by previous studies exploring factors that influence the willingness of older adults to use technology for aging in place, as indicated by a review performed by Peek et al. [21].

\section{Acknowledgements}

This publication has been financed in part by the subsidy granted to Cracow University of Economics, Poland.

\section{References}

[1] S. Blackman, C. Matlo, C. Bobrovitskiy, et al. "Ambient assisted living technologies for aging well: a scoping review," Journal of Intelligent Systems, (25:1), 2015, pp. 55-69.

[2] D.E. Bloom, et al. "Macroeconomic implications of population ageing and selected policy responses", Lancet (385:9968), 2015, pp. 649-657.

[3] G. Dhillon, and G. Torkzadeh, "Value-focused assessment of information system security in organizations", Information Systems Journal (16:3), 2006, pp. 293-314.

[4] European Commission, "DESI 2019 Digital Economy and Society Index Methodological Note", https://ec.europa.eu/digital-single-market/en/desi, 2019.

[5] L. Foster, and A. Walker, "Active and successful aging: A European policy perspective", The Gerontologist (55:1), 2015, pp. 83-90.

[6] J. Fritzell, C. Lennartsson, and A. Zaidi, "Trends and Inequality in the New Active Ageing and Well-Being Index of the Oldest Old: a Case Study of Sweden", Population Ageing, https://doi.org/10.1007/s12062-02009264-9, 2020.

[7] R. Gregory, and R.L. Keeney, "Creating policy alternatives using stakeholder values", Management Science (40:8), 1994, pp. 1035-1048.

[8] S. Harper, "Economic and social implications of aging societies", Science (346:6209), 2014, pp. 587-591.

[9] K. Hedström, E. Kolkowska, F. Karlsson, and J.P. Allen, "Value conflicts for information security management", The Journal of Strategic Information Systems (20:4), 2011, pp. 373-384.

[10] G. Hofstede, Culture's Consequences: Comparing, Values, Behaviours, Institutions and Organizations Across Nations (Second ed.), Sage, Beverly Hills, CA, 1980.

[11] A. Ihle, É.R. Gouveia, B.R. Gouveia, B.W.A. van der Linden, J. Sauter, R. Gabriel, M. Oris, D. Fagot, and M. Kliegel, "The Role of Leisure Activities in Mediating the Relationship between Physical Health and WellBeing: Differential Patterns in Old and Very Old Age", Gerontology (63:6), 2017, pp. 560-571. 
[12] R.L. Keeney, Value-Focused Thinking, Harvard University Press, Cambridge, MA, 1992.

[13] R.L. Keeney, "Creativity in decision making with valuefocused thinking", Sloan Management Review (35), 1994, pp. 33-41.

[14] A. Klimczuk, "Comparative analysis of national and regional models of the silver economy in the European Union”, International Journal of Ageing and Later Life (10:2), 2016, pp. 31-59.

[15] C. Kluckhohn, (Ed.) Values and Value Orientations in the Theory of Action: An Exploration in Definition and Classification, Harvard University Press, Cambridge, MA, 1951.

[16] E. Kolkowska, E. Soja, and P. Soja, "Implementation of ICT for Active and Healthy Ageing: Comparing ValueBased Objectives Between Polish and Swedish Seniors", in SIGSAND/PLAIS 2018. LNBIP, vol. 333, S. Wrycza and J. Maślankowski (eds.), 2018, pp. 161173.

[17] M. Kraus, M. Riedel, E. Mot, P. Willemé, G. Röhrling, and T. Czypionka, "A typology of long-term care systems in Europe", ANCIEN Project, ENEPRI Research Report No 91, Brussels, Belgium: CEPS, 2010.

[18] W. Lutz, W. Sanderson, and S. Scherbov, "The coming acceleration of global population ageing", Nature (451), 2008, pp. 716-719.

[19] J. May, G. Dhillon, and M. Caldeira, "Defining valuebased objectives for ERP systems planning", Decision Support Systems (55:1), 2013, pp. 98-109.

[20] M.E. Paggi, D. Jopp, and C. Hertzog, "The Importance of Leisure Activities in the Relationship between Physical Health and Well-Being in a Life Span Sample", Gerontology (62:4), 2016, pp. 450-458.

[21] S.T.M. Peek, E.J.M. Wouters, J. van Hoof, K.G. Luijkx, H.R. Boeije, and H.J.M. Vrijhoef, "Factors influencing acceptance of technology for aging in place: A systematic review", International Journal of Medical Informatics (83:4), 2014, pp. 235-248.

[22] D.R. Philips, and O. Siu, "Global aging and aging workers", in Hedge, J.W. and Borman, W.C.(Eds), The Oxford Handbook of Work and Aging, Oxford Library of Psychology, Oxford, 2012, pp. 11-32.

[23] N. Rescher, Introduction to value theory, Prentice-Hall, Englewood Cliffs, 1969.

[24] M. Rigby, S. Koch, D. Keeling, P. Hill, A. Alonso, and E. Maeckelberghe, Developing a New Understanding of Enabling Health and Wellbeing in Europe: Harmonising Health and Social Care Delivery and Informatics Support to Ensure Holistic Care, European Science Foundation, Strasbourg, France, 2013.
[25] J.M. São José, V. Timonen, C.A. Amado, and S.P. Santos, "A critique of the Active Ageing Index", Journal of Aging Studies (40), 2017, pp. 49-56.

[26] V.F. Skirbekk, U.M. Staudinger, and J.E. Cohen, "How to Measure Population Aging? The Answer Is Less than Obvious: A Review", Gerontology (65:2), 2019, pp. 136-144.

[27] E. Soja, P. Soja, E. Kolkowska, and M. Kirikova, "Supporting Active and Healthy Ageing by ICT Solutions", in SIGSAND/PLAIS 2019. LNBIP, vol. 359, S. Wrycza and J. Maślankowski (eds.), 2019, pp. 48-61.

[28] P. Soja, and P.R. Cunha, "ICT in transition economies: narrowing the research gap to developed countries", Information Technology for Development (21:3), 2015, pp. 323-329.

[29] M. Tambor, and M. Pavlova, Can people afford to pay for health care? New evidence on financial protection in Poland, WHO Regional Office for Europe, Copenhagen, 2020.

[30] F.B. Tan, and G.M. Hunter, "The Repertory Grid Technique: A Method for the Study of Cognition in Information Systems", MIS Quarterly (26:1), 2002, pp. 39-57.

[31] UNECE / European Commission, 2018 Active Ageing Index: Analytical Report, Report prepared by Giovanni Lamura and Andrea Principi under contract with the United Nations Economic Commission for Europe (Geneva), co-funded by the European Commission's Directorate General for Employment, Social Affairs and Inclusion, Brussels, 2019.

[32] A. Walker, and T. Maltby, "Active ageing: A strategic policy solution to demographic ageing in the European Union", International Journal of Social Welfare (21:1), 2012, pp. 117-130.

[33] K.E. Weick, Sensemaking in Organizations, Sage Publications, Beverly Hills, CA, 1995.

[34] World Health Organization (WHO), Active Ageing - A Policy Framework, A contribution of the World Health Organization to the Second United Nations World Assembly on Ageing, Madrid, April, 2002.

[35] World Health Organization (WHO), Report on the WHO Symposium on the Future of Digital Health Systems in the European Region, Copenhagen, Denmark, 6-8 February 2019, WHO Regional Office for Europe, Copenhagen, 2019.

[36] A. Zaidi, K. Gasior, E. Zolyomi, A. Schmidt, R. Rodrigues, and B. Marin, "Measuring active and healthy ageing in Europe", Journal of European Social Policy (27:2), 2017, pp. 138-157. 